\title{
Brasil: o futuro da economia
}

\author{
GUILHERME LEITE DA SILVA DIAS
}

\section{Introdução}

$\mathrm{Q}$

UANDO PROCURAMOS levantar uma discussão sobre a relação entre poupança e investimento, é freqüente o debate cair para o academicismo dos livros-texto de economia, nos quais predomina a versão keynesiana de que são os găstos de consumo/investimentos que determinam a poupança requerida. As evidências empíricas também parecem corroborar a hipótese de que os gastos em investimentos tendem a preceder os movimentos de poupança. Quando, no entanto, o tema é colocado da perspectiva do desenvolvimento econômico, ocorrem muitas situações nas quais o investimento foi na frente, mas a poupança doméstica não apareceu para salvar a crença de muitos.

O Brasil, infelizmente, é um exemplo desses episódios. Depois de viver por mais de 25 anos uma experiência de industrialização bem-sucedida, quando imaginávamos que tinha chegado o momento da autodeterminação, mergulhamos numa crise de endividamento sem fim.

A proposição deste artigo é chamar atenção para a falta de dinamismo da poupança doméstica já naqueles anos dourados, mesmo quando o investimento era elevado, antes da ruptura do modelo nacional-desenvolvimentista. As causas do baixo dinamismo podem ser encontradas na literatura que analisou a especificidade do nosso capitalismo dependente; a conseqüência importante dele para o momento atual, para aqueles que sonham com o desenvolvimento sustentável, está na diferença de prioridades na agenda de política econômica. Não vamos sugerir que todas as reformas econômicas estão equivocadas, mas sim que elas não produziram os efeitos esperados, e não o farão se seguirmos a receita completa, porque faltam os agentes econômicos básicos (capitalista nacional, multinacional, burocrata e consumidor) como entidades reais detentoras de poder econômico e de representatividade política, temidas umas pelas outras e, portanto, respeitando a regra do jogo (desenvolvimento).

Antes da análise desses pontos, é conveniente ilustrar o debate com algumas referências atuais. A primeira vem de Dionísio Dias Carneiro (2003):

Por que os investidores privados não gastam mais em aquisições de máquinas e equipamentos, construções e projetos de inovação e treinamento, que formam o alicerce do crescimento econômico? [...] De fato, há duas fontes de incerteza macroeconômica para os investidores: a falta de clareza quanto aos impostos futuros [...] e risco de que o setor privado possa ser deslocado nos mercados de crédito, a qualquer hora, pelo peso de uma dívida pública descontrolada. Estas dúvidas recomendam políticas que reduzam as incertezas [...] Pois há desconfiança na sustentabilidade da dívida pública, caso esta seja sus- 
tentada apenas por mais impostos [...] Para melhorar a alocação da poupança, é preciso maior confiança nas regras básicas e o reforço das instituições econômicas, assuntos em que o governo está pouco convincente. É impossível não contrastar esse requisito com a idéia de "coragem" para aumentar impostos, que sublinha a discussão da reforma tributária, ou a "coragem" para aumentar gastos, objeto da disputa entre os diversos ministérios no orçamento de 2004.

Segue-se que o desafio de aumentar a poupança é menos relevante do que o de controlar a dívida pública, ou de que o interesse em receber a renda proporcionada pela remuneração da dívida não seja mais atraente para outros grupos detentores de grande poder. A outra ilustração vem de Delfim Netto (2004), com sua ironia característica:

A poupança exigida na identidade (déficit em conta corrente $=$ investimento poupança interna) se produz não - como sempre esperaram alguns $\mathrm{PhDs}$ pela disposição da população em reduzir o seu consumo, ou por motivos estéticos ou patrióticos, mas por força do funcionamento do sistema de preços. Quando a taxa de câmbio real procura o seu equilíbrio, ela reduz, através da modificação dos preços relativos entre bens exportáveis e não-exportáveis, $o$ nível de consumo. Quando o Banco Central impede que a mudança de preços relativos se transforme em inflação (elevando a taxa de juro), reduz-se o investimento. Quando há responsabilidade fiscal, as variáveis realmente exógenas são o investimento e o consumo do governo, que são controlados. É a somatória da redução do consumo, do investimento e dos gastos do governo que produz os valores que mantém a identidade acima, mas altera a sua composição. A tal "poupança" procurada por alguns economistas (e que deveria ter sido tomada emprestada do Espírito Santo) é produzida pelo funcionamento do sistema de preços.

Segue-se, então, que burocratas podem determinar as variáveis que sustentam os preços relativos adequados, e os outros agentes não contestam essa estrutura de preços relativos. A última ilustração é de Yoshiaki Nakano (2004):

Num país como o Brasil, a poupança privada é composta fundamentalmente de lucros retidos. Por esta razão, é lógico que a taxa de poupança não está relacionada com a taxa de juros, mas com a taxa de crescimento da economia [...] Podemos sugerir duas políticas para promover a retomada do crescimento, estimulando simultaneamente os investimentos e as poupanças necessárias para financiá-los. A primeira política estimula os investimentos através da redução na tributação dos lucros retidos e da depreciação acelerada [...] Uma segunda política, a de desvalorização cambial, atuaria da mesma forma [...] geramos uma nova demanda ao tornarmos os nossos produtos mais competitivos no Exterior, incrementando os investimentos [...] Ao mesmo tempo, a desvalorização cambial significa que os salários, em dólar, diminuem e ficam menores do que no Exterior, e assim estas empresas exportadoras passam a ter uma vantagem em termos de custo, podendo capturar um lucro extraordinário e financiar os seus acréscimos de investimentos.

Segue-se que as despesas públicas se reduzem, ou outros impostos serão elevados sem questionamentos por demais agentes; no segundo caso, o custo de 
vida subindo pelo efeito do câmbio desvalorizado reduz a renda real dos consumidores assalariados, diminuindo o lucro dos que vendem para o mercado interno, também sem questionamentos.

\section{Recuperando fatos relevantes} sobre o processo comparado de desenvolvimento

Nos Gráficos 1 e 2, podemos observar que os quatro países que apresentaram taxas de poupança bruta doméstica acima de 30\% do PIB constituem casos inequívocos de sucesso nos últimos 25 anos (Malásia, Coréia, Tailândia e Irlanda). A Indonésia é um caso intermediário, apresentando resultados medíocres depois da crise asiática de financiamento de 1997, quando cai para um nível de poupança de $25 \%$. O Chile é outro caso intermediário, mas que, ao contrário da Indonésia, conseguiu estabilizar sua taxa de poupança doméstica nos $25 \%$ do PIB, desde meados dos anos 1980, apresentando uma taxa de crescimento acima da média dos países emergentes. Brasil e México completam a lista, e são casos de crescimento medíocre nas duas últimas décadas; os dois não conseguiram sustentar taxas de poupança acima dos $20 \%$. No caso do México, a transformação proporcionada pelo Nafta, depois de 1994, provocou apenas um fenômeno passageiro de aceleração do crescimento apoiado na poupança externa.

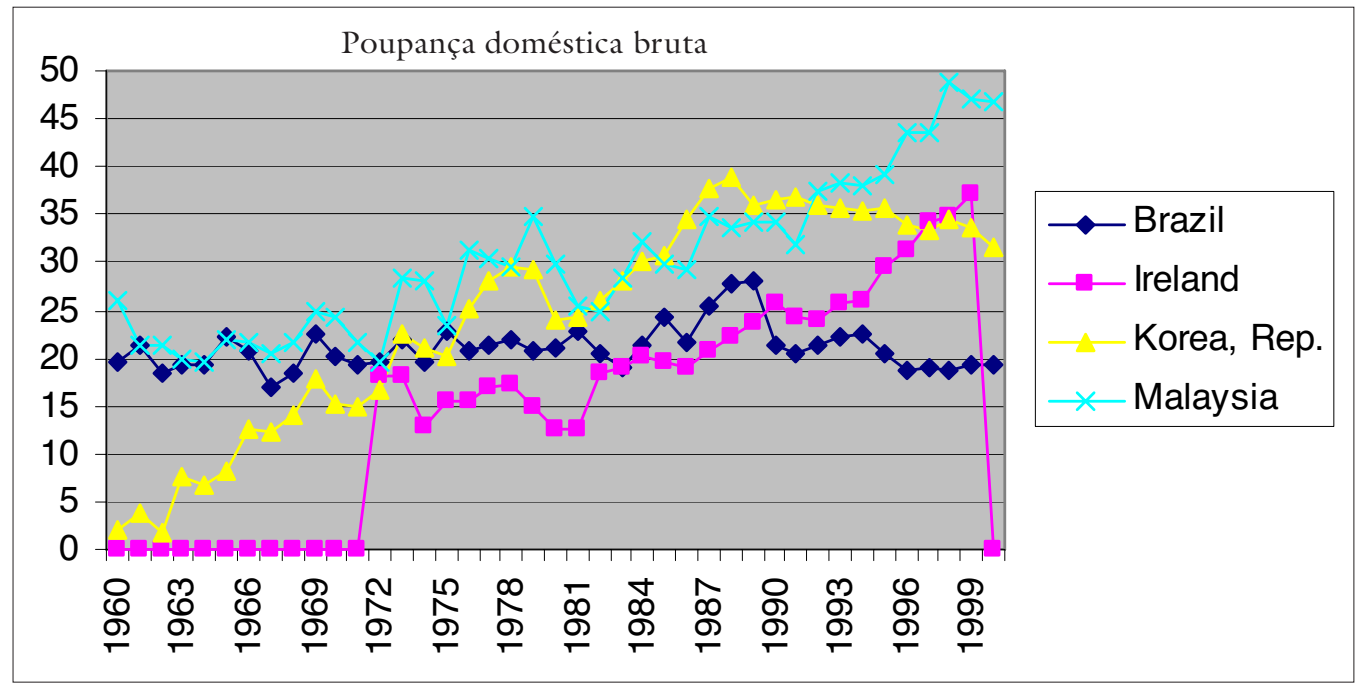

Fonte: WDI do Banco Mundial.

Gráfico l - Taxas brutas de poupança doméstica I, 1960-2002.

Esses fatos nos trazem de volta um conceito básico da teoria do desenvolvimento econômico dos anos 1950, a saber, de que tal processo, para ser sustentado, depende de um esforço coletivo especial capaz de romper com o status quo característico do subdesenvolvimento. O Estado, pela sua burocracia, e as novas elites empresariais precisam estar de acordo na sustentação de um grande período de investimentos transformadores, e o resultado final depende de uma com- 
binação entre a formação de um grande mercado consumidor doméstico e a consolidação de uma capacidade competitiva no mercado internacional. O fortalecimento do mercado doméstico traz consigo a incorporação da massa assalariada ao processo de poupança doméstica, geralmente por meio de um amplo sistema de previdência social compulsória, e a competitividade externa reforça a capacidade de poupança das grandes empresas exportadoras.

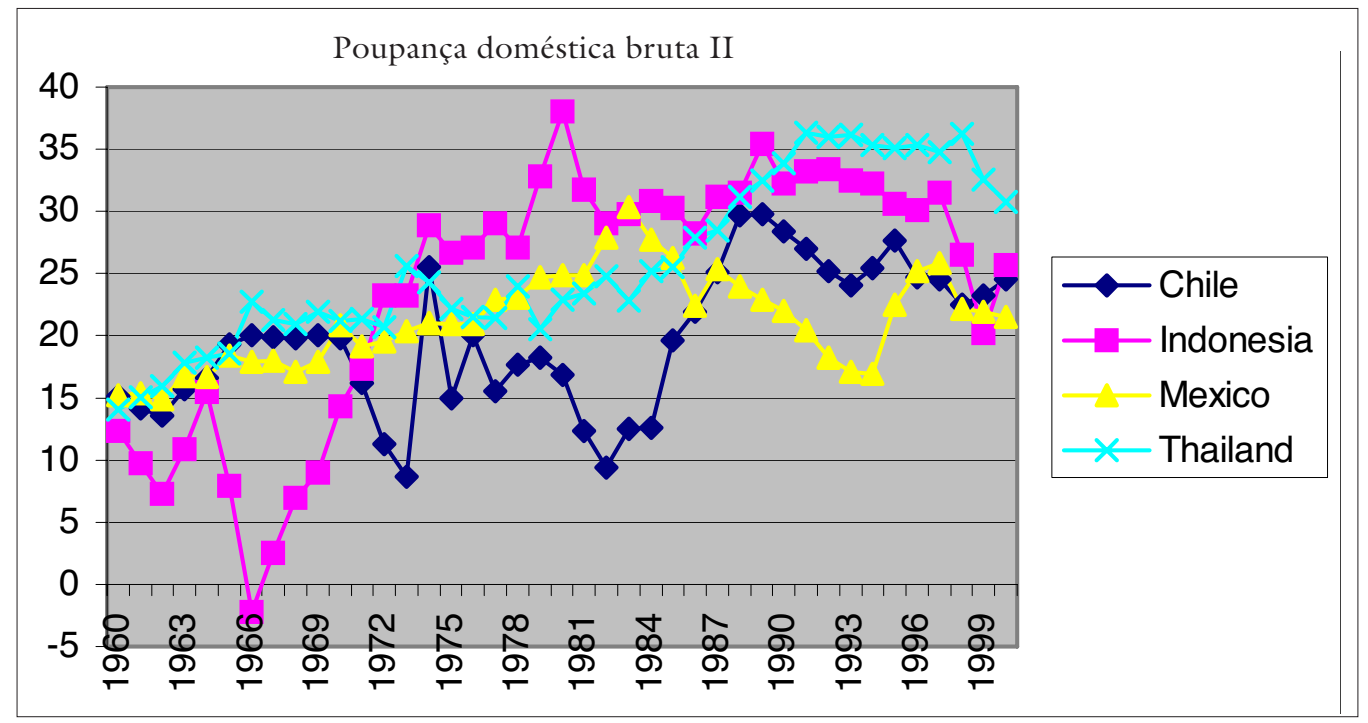

Fonte: WDI do Banco Mundial.

Gráfico 2 - Taxas brutas de poupança doméstica II, 1960-2002.

Quase todos os países em desenvolvimento que tiveram dificuldade de incorporar os novos setores produtivos ao processo de poupança doméstica tiveram de recorrer, de modo temerário, ao endividamento externo. Diante da volatilidade do mercado internacional de capitais, depois da flutuação das taxas de câmbio das principais economias desenvolvidas, todos tiveram de abortar seus projetos de desenvolvimento por insuficiência de poupança doméstica. A necessidade de reorientar uma parcela expressiva da renda doméstica para o pagamento externo de juros e principal da dívida rompeu com o que havia de acordo interno para sustentar aquele grande esforço coletivo.

Dentre aqueles que analisaram o desenvolvimento das economias latinoamericanas, quem melhor descreveu esse processo foi Albert Hirshman (1968), chamando atenção para a característica básica da industrialização "muito atrasada" (late-late comers), na qual predominam a imitação e a importação de processos já testados, sem a sustentação de uma experimentação tecnológica e o concomitante treinamento em inovação, que eram características das nações pioneiras (ibidem, p.8).

A classe empresarial é mais uma extensão dos importadores; são dependentes da capacidade de exportação dos produtores primários e dos fornecedores de 
crédito comercial, tornando difícil a substituição dessa elite tradicional na liderança do processo político. A continuidade do processo de substituição de importações vai depender da capacidade de superar limitações de tamanho do mercado doméstico (escala mínima nos produtos intermediários entre bens de consumo final e bens de capital), o que requer uma intervenção política do Estado, gerando a instalação simultânea de outras indústrias que gerem aumento da demanda por aqueles bens intermediários. A escolha do nível de proteção que será oferecida a essas novas indústrias altera a margem de lucro dos empreendedores das primeiras indústrias, o que reforça o papel político da burocracia. As suas decisões discretas diminuem o papel da acumulação de lucros na atividade empresarial como o principal mecanismo de galgar níveis de integração vertical, ou seja, a formação de complexos industriais sob o controle do próprio empresariado (ibidem, p.24).

As tarifas de importação e a taxa de câmbio são elementos importantes nessa equação que define a capacidade de investir nas novas oportunidades de substituição de importações; portanto, são motivos de discórdia entre os novos empresários e as elites tradicionais de produtores primários. A aliança entre os novos empresários e a burocracia vai ser feita em torno da exploração da inflação e da sobrevalorização cambial como forma de manter as margens de lucro e socializar o custo das dívidas. Esse conjunto de instrumentos de política econômica vai inibindo uma ação coletiva pela elevação da taxa de poupança doméstica.

\section{Recuperando fatos relevantes}

\section{da experiência brasileira com o desenvolvimento}

No caso brasileiro, o Estado toma o papel de articulador da transformação da economia. Os novos empresários industriais nunca se sentiram no controle das políticas econômicas vitais aos seus interesses. A burocracia de fato cultivou certa distância dos grupos de interesse, preferiu certa imprevisibilidade e um caráter manipulador. Isso fica claro nos anos 1960, quando enfrentamos a primeira crise cíclica, com formação de capacidade ociosa, que apontava para a exportação de manufaturados como forma de retomada do crescimento. O governo militar, no entanto, vai preferir um intrincado esquema de subsídios com créditos fiscais, somado a financiamentos subsidiados. Todos esses mecanismos são discricionários, não contribuem para a consolidação de uma sólida confiança no Estado como parceiro de uma política de industrialização.

A implementação desse modelo, do segundo governo Vargas ao de Kubitschek, tinha como desafio a elevação da taxa de poupança doméstica e como estratégia uma forte ação do Estado, redistribuindo o excedente na mão do setor privado, especialmente do agrário exportador, para o novo setor industrial. $\mathrm{O}$ próprio Estado se apropriava de parte desse excedente quando criava empresas em setores produtores de insumos estratégicos nos quais faltava competência ao empresário nacional ou a presença dominante do capital estrangeiro representava um risco estratégico elevado. A poupança doméstica requerida para esse esfor- 
ço inicial de crescimento não poderia ficar à mercê das oscilações cíclicas da conjuntura internacional, e muito menos na mão de centros de decisão nas economias capitalistas centrais. Mesmo depois dos tropeços no governo Jânio-Jango, militares e burocratas conseguiram rearticular a coordenação do modelo num grande impulso de crescimento até meados dos anos 1970.

O Gráfico 3 mostra como evoluiu a taxa bruta de poupança doméstica entre 1947 e 2003, assim como o PIB e per capita. Podemos observar que em meados da década de 1970 já existe uma reversão no padrão de crescimento da taxa de poupança, que até então crescia aceleradamente desde 1947 (até esse ponto, a poupança externa é subsidiária e incapaz de gerar uma ruptura no processo). Esse foi o primeiro sinal de uma desarticulação grave no padrão de incentivos ao setor privado e na gestão do orçamento público que é a raiz de nossa vulnerabilidade externa. Até hoje não foi possível retomar um padrão consistente de elevação na taxa bruta de poupança, o que sugere procurar também no plano doméstico uma importante restrição ao nosso processo de crescimento; cabe lembrar que esse processo precede o surto elevado de endividamento externo. Voltaremos a esse ponto mais adiante.

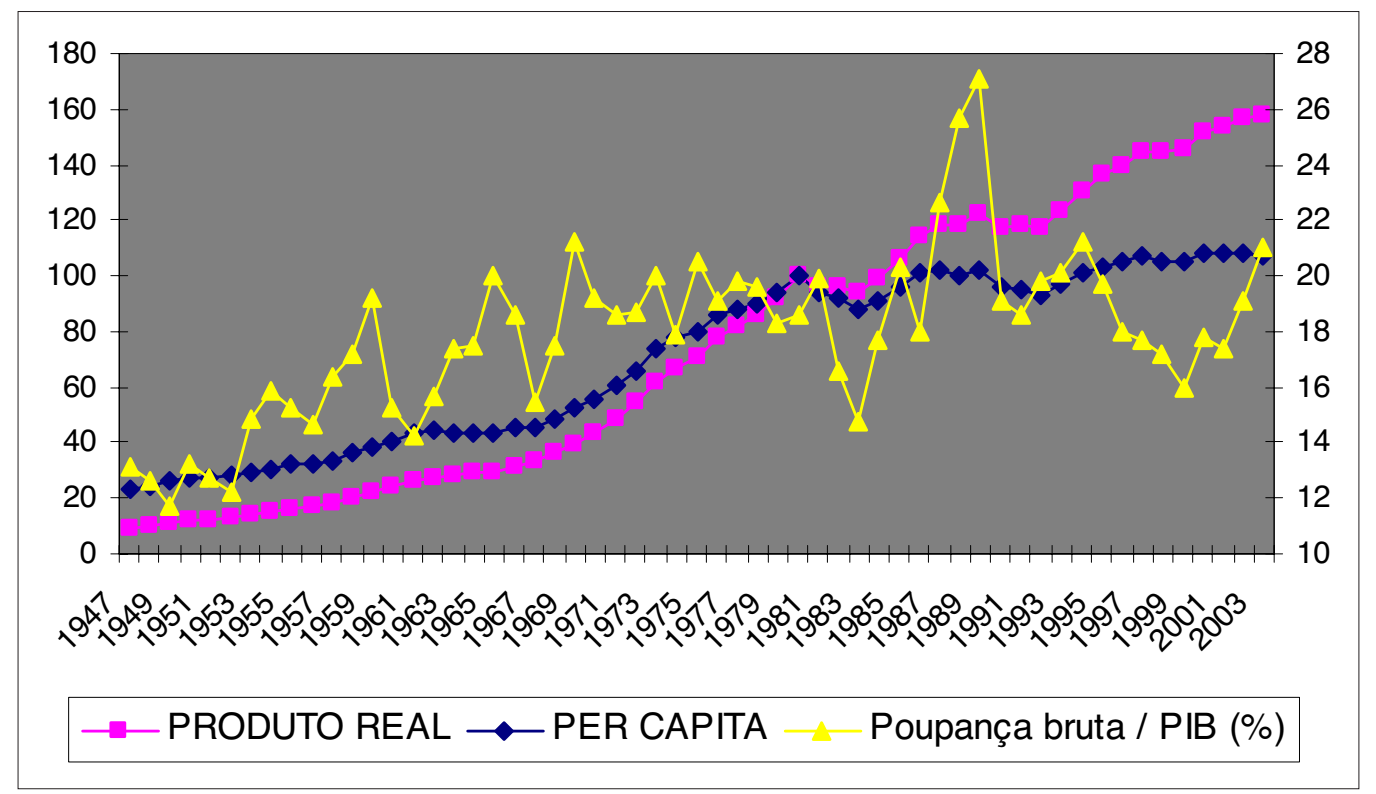

Fonte: Contas Nacionais, IBGE.

Gráfico 3 - PIB e poupança bruta no Brasil, 1947-2003.

O Gráfico 4 oferece uma informação relevante para explicar a natureza do financiamento do crescimento mais acelerado da economia até 1980, a partir de quando fica caracterizada uma forte redução no crescimento do produto per capita. Em 1970, ocorre uma redução acentuada na poupança do setor privado e sua substituição por um também acentuado crescimento da poupança do setor 
público (no Gráfico 4, corresponde à diferença entre a bruta e a privada). Esse período corresponde à maturação das reformas estruturais promovidas pelos governos militares: a fiscal, em 1967, e no mercado financeiro e de capitais, em 1968 e 1969. Existe aí um crowding-out da poupança privada e a origem de uma quebra de confiança na parceria público-privada, fundamental para o sucesso inicial do modelo de substituição de importações. Essa quebra de confiança tem um efeito letal para a formação de um mercado de contratos de longo prazo, exclui uma rota de captação de poupança mediante um modelo de previdência social de capitalização e um mercado financeiro mais completo, fato presente em todos aqueles outros casos vistos anteriormente de crescimento bem-sucedido.

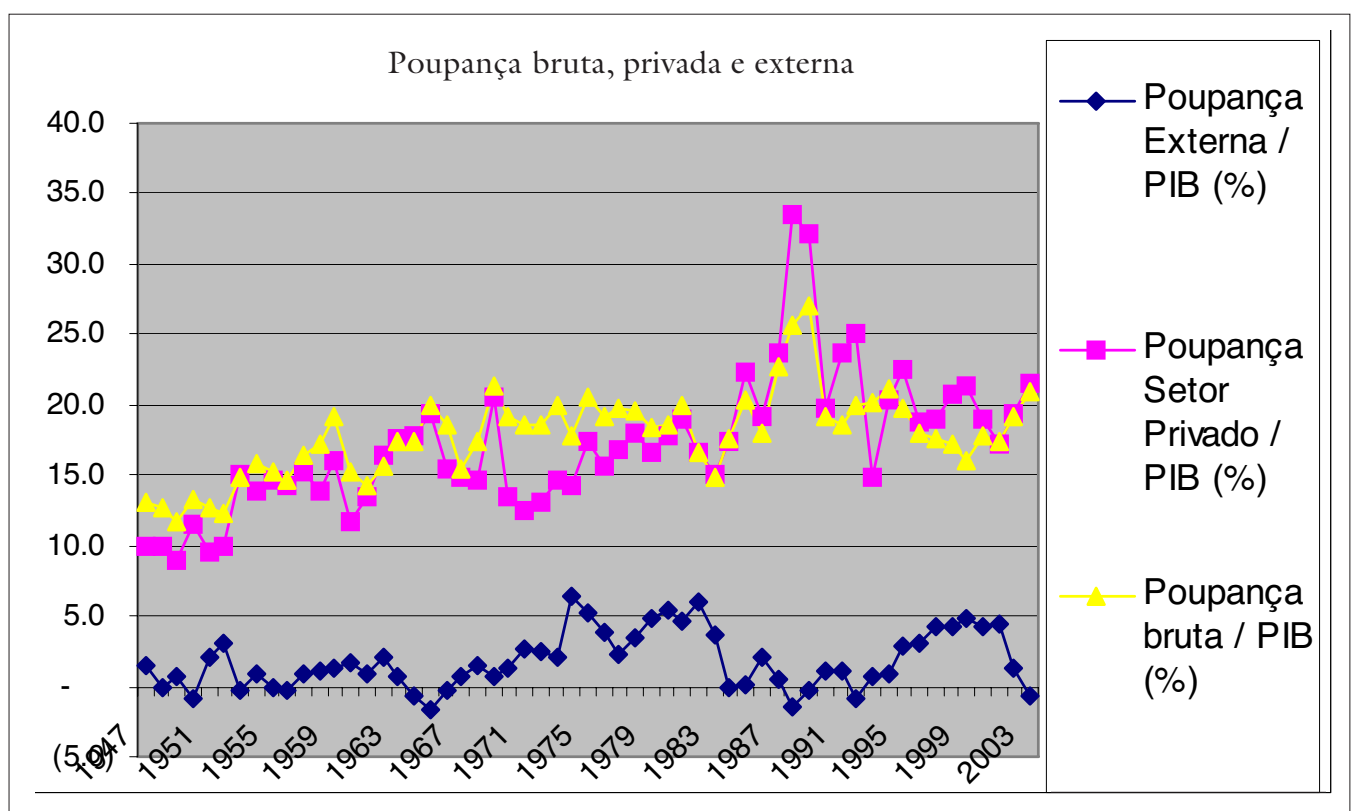

Fonte: Contas Nacionais, IBGE.

Gráfico 4 - Poupança bruta, privada e externa no Brasil, 1947-2003.

O II Plano Nacional de Desenvolvimento (PND) vem no rastro desse processo de mobilização da poupança bruta pelo setor público, consolidando a implantação de um parque industrial completo. Diante da incapacidade de promover uma elevação da poupança bruta doméstica, a implementação do II PND vai recorrer à poupança externa. No plano inicial, ela viria pela parceria com o capital externo; na prática, ela veio pelo novo sistema financeiro internacional que surgira no início da década de 1970. Ocorre nesse ciclo de crescimento uma renovação do empresariado nacional, agora no contexto de cadeias industriais completas, nas quais a governança está concentrada em empresas estatais ou multinacionais, e de um intrincado conjunto de organismos burocráticos que gerenciam tabelas de preços, tarifas, quotas de importação, subsídios em créditos dirigidos e cargas tributárias diferenciadas. Essa configuração não estimula a 
poupança e a formação de um mercado de capital doméstico, em virtude do caráter discricionário de tal conjunto de incentivos. O Estado reforçou seu controle sobre a insuficiente poupança doméstica e, por meio da política cambial, deu o seu aval para o capital financeiro externo.

Nesse ponto, cabe uma digressão sobre a natureza do capitalismo dependente, segundo as observações de Luciano Martins (1985, p.34): o Estado além de se interpor "às classes dominantes e às classes a elas subordinadas enquanto mediador $[\ldots]$ dos conflitos $[\ldots]$ (também) intervém enquanto ator ao nível das relações de produção [...] e é por ele ampliado pela própria lógica de sua intervenção [...] e, também, pelos interesses de sua burocracia". A conseqüência importante apontada é que é dentro do aparelho do Estado que se expressam os conflitos e de cujas decisões de poder se projeta uma "autonomia relativa" do Estado sobre a sociedade civil. Num cenário com essas características, é difícil imaginar um ambiente de cooperação entre setor privado e público para um processo continuado de elevação da poupança bruta doméstica.

\section{Recuperando fatos sobre a ruptura do modelo de desenvolvimento}

O sucesso desse modelo ficou comprometido por uma série de razões. A mais analisada foi a crise do endividamento externo. Suas múltiplas manifestações desde o início dos anos de 1980 são, de fato, conseqüência de algo mais grave, que foi o esgotamento do padrão de financiamento do modelo de industrialização, como apontado por Lídia Goldenstein (1994).

Entre os anos de 1977 e 1978, começaram a surgir sinais de que os empresários nacionais, de segunda geração, não queriam continuar investindo e assumindo o risco do financiamento externo. $\mathrm{O}$ risco era elevado porque a maior parte da expansão da produção estava dirigida para o mercado interno, com a receita denominada em moeda doméstica e o endividamento denominado em moeda externa. A troca do risco só seria possível com uma expansão do endividamento interno e a assunção do risco externo pelo governo (ibidem, p.89). As empresas estatais, o Banco Central, o Tesouro Nacional e as instituições financeiras públicas fazem essa conversão. Começa a ciranda financeira, na qual elevações da taxa de juros nominal, da inflação e da remarcação de preços e salários promovem um acirramento do conflito distributivo, com a aceleração da inflação e do endividamento público. O importante aqui é não confundir a manifestação financeira com a crise de fundo que é a ruptura do padrão de financiamento, “(que) é expressão da forma de organização capitalista, cuja constituição, no caso brasileiro, impossibilitou a formação de uma base financeira nacional, resultando uma carência crônica de financiamento de longo prazo e um inchaço especulativo do mercado financeiro" (ibidem, p.94).

Outra razão para a desestruturação do processo de crescimento está ligada à natureza da dinâmica do modelo de substituição de importações implantado. A demanda final por bens de consumo no mercado interno teria de manter uma 
taxa de crescimento muito elevada para induzir a sustentação do nível de investimentos e da demanda por bens de capital domésticos. A participação na renda dos gastos de consumo domiciliares teria de crescer, o que seria compatível apenas com um cenário de salário real e empregos em franco crescimento. A crise do financiamento externo, no entanto, requer uma forte desvalorização real da moeda doméstica, enquanto o refinanciamento da dívida pública requer uma taxa de juros real elevada.

Uma razão adicional foi de ordem externa - a globalização, com novos processos de produção, gerando fortes economias de escala, e a inovadora tecnologia de informação vão comprometer, ao longo da década de 1980, a competitividade de nosso setor produtivo manufatureiro (ibidem). Os empresários de primeira e segunda gerações não confiam mais no Estado e resistem a essa necessidade de reestruturação, como ficou evidente na defesa intransigente das prerrogativas de reserva do mercado doméstico, durante as negociações da Constituição de 1988. A constitucionalização de instrumentos de gestão da economia, antes na mão da burocracia, foi uma tentativa extrema dos empresários nacionais de reconquistar um papel relevante, implícito no modelo nacional-desenvolvimentista.

A abertura comercial e o início da privatização de muitas empresas estatais, a partir do governo Collor, vieram promover a reestruturação do sistema produtivo para os novos padrões de competição. A governança de muitas cadeias produtivas passa para as mãos de grandes grupos multinacionais, o que garantiu o apoio das agências multilaterais de financiamento e o aporte de capital externo para a renegociação bem-sucedida da dívida externa brasileira, entre 1992 e 1994.

A privatização no setor de serviços públicos, no entanto, colocou o capital externo numa posição de alto risco. Com a sua receita em moeda doméstica, é ele que corre o risco de não poder remunerar adequadamente a matriz externa. A necessidade urgente de cobrir o déficit crescente em contas correntes levou o governo Fernando Henrique Cardoso a indexar parcialmente o preço desses serviços públicos ao câmbio. Uma parcela expressiva dos empresários nacionais, em especial aqueles que venderam suas empresas para multinacionais, ficou com o dilema de enviar seus recursos para o exterior (fuga de capital), reinvestir nos novos nichos de oportunidade (originados pela reestruturação produtiva), ou aplicar nos títulos de dívida pública (a ciranda financeira). O fato de que, depois do início da década de 1990, a poupança privada se estabilizou em torno de $20 \%$ do PIB sugere que a alternativa de "saída" (Hirschman, 1970) teve um peso destacado no comportamento dos nossos capitalistas. A assessoria da CPI do Banestado constatou que, do total de 412 mil operações de remessas de recursos realizadas no período de 1996 a 2002, os campos identificadores do banco e da conta no exterior beneficiada estavam em branco em quase 390 mil - 94,6\% do total; ou seja, são operações que não poderão ser rastreadas ou que a Receita Federal terá uma dificuldade muito grande em fazê-lo. 
É interessante observar que outros economistas utilizando modelos de analise muito diferentes, como o usado por Bacha \& Bonelli (2005), também chegam ao mesmo diagnóstico de rompimento no processo, aqui de crescimento e não de desenvolvimento. A Tabela 1 indica, na sua segunda coluna (crescimento do estoque de capital em relação ao trabalho efetivo), que o aprofundamento da cadeia de industrialização, depois de 1974, trouxe como conseqüência uma forte perda de produtividade do trabalho e do conjunto dos fatores de produção (quarta e quinta colunas, respectivamente). Em outras palavras, o sistema de produção ficou ineficiente, e duas décadas depois (com abertura econômica e reestruturação industrial) a eficiência econômica retorna, mas sem fôlego, em virtude da baixa taxa de investimentos (interação entre a segunda e a terceira colunas). O principal fator apontado no texto para explicar essa disfunção do processo de crescimento está na acentuada elevação do preço relativo dos investimentos durante a década de 1980. Curiosamente, isso nos traz de volta o processo que Hirschman indicou em 1968 - imitar processos de produção cada vez mais complexos sem desenvolver a capacidade de experimentação tecnológica e o treinamento em inovação, ou seja, o empresário capitalista das economias centrais.

Tabela 1 - Decomposição alternativa das taxas de crescimento do PIB (modelo de Solow-Swan, 1942-2002)

\begin{tabular}{|l|c|c|c|c|c|}
\hline Períodos & $\mathbf{Y}^{\prime}$ & $\mathbf{( 1 / v )}$ & $\mathbf{L}^{\prime}$ & $\mathbf{A}^{\prime}$ & A'/Y'(\%) $^{\prime}$ \\
\hline $1942-1952$ & 0,069 & 0,011 & 0,021 & 0,035 & 51,1 \\
\hline $1952-1964$ & 0,067 & 0,008 & 0,025 & 0,032 & 48,1 \\
\hline $1964-1974$ & 0,088 & 0,002 & 0,032 & 0,052 & 59,0 \\
\hline $1974-1984$ & 0,039 & 0,026 & 0,031 & 0,017 & $-43,5$ \\
\hline $1984-1993$ & 0,025 & 0,008 & 0,025 & $-0,008$ & $-32,0$ \\
\hline $1993-2002$ & 0,027 & $-0,001$ & 0,016 & 0,012 & 43,1 \\
\hline
\end{tabular}

Fonte: Bacha \& Bonelli (2005).

Nota: coluna $\mathrm{l}$ = taxa de crescimento do PIB; col. 2 = diferença entre o crescimento do estoque de capital e do trabalho efetivo; col. 3 = taxa de crescimento do emprego; col. $4=$ taxa de progresso técnico ampliador do trabalho; col. 5 = parcela do crescimento do PIB explicada pela produtividade total dos fatores.

Sem um padrão definido de progresso tecnológico e sem um acordo político-institucional abrangente sobre os mecanismos de regulação do nosso processo de desenvolvimento, não podemos manifestar estranheza diante do quadro estático da distribuição de renda, talvez o mais agressivo entre as economias emergentes nos últimos cinqüenta anos (exceção provável da Indonésia) (Gráfico 5).

\section{Procurando identificar os fatos portadores do futuro}

Neste ponto retomamos a questão do papel estratégico da poupança doméstica; o que foi sugerido no início deste artigo é a importância do padrão de 


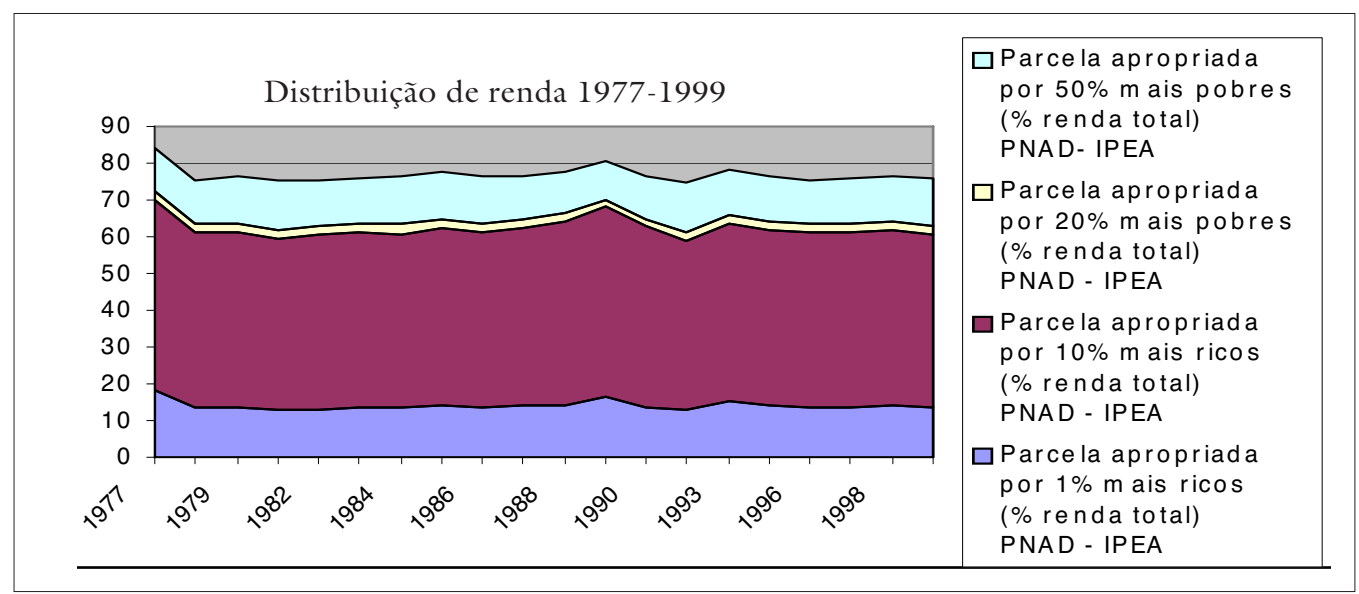

Fonte: Contas Nacionais, IBGE.

Gráfico 5 - Distribuição da renda, 1977-1999.

evolução dessa taxa ao longo de um prazo suficiente para revelar a atitude dos grandes detentores da renda nacional. As diferentes formas de poupança, desde a caderneta de poupança do chefe de um domicílio até o maior fundo de aposentadoria, representam manifestações de confiança no futuro da nação e nas atitudes de cooperação entre agentes econômicos. Algumas nações revelam uma capacidade excepcional de articular um longo ciclo de crescimento, atingindo patamares superiores a 30\% do PIB. Quando conseguem associar esse comportamento com a capacidade de realizar experimentos tecnológicos e treinamentos na inovação de produtos, ganham a condição de países centrais, com controle social sobre o seu processo de reprodução e de expansão pela economia internacional.

Vimos alguns indícios de que o nosso processo de desenvolvimento está incompleto e, mais preocupante, apresentando sinais de desarticulação entre as instituições coordenadoras dos agentes privados, públicos e internacionais. Tanto a burocracia do "Estado Empresário" quanto as sucessivas gerações de donos de empresas privadas foram incapazes de articular um ciclo virtuoso da poupança doméstica com aquelas características destacadas antes. Nesse espaço vazio, as agências multilaterais e os governantes dos países centrais promovem incentivos, às vezes impõem reformas pontuais no aparato regulador da nossa economia, como a abertura da economia, o controle centralizado das finanças públicas e um sistema financeiro articulado com o internacional. O que procuramos destacar é que o processo político que determina a articulação entre as ações típicas do Estado e dos principais agentes detentores da riqueza nacional é que define as opções estratégicas possíveis em cada momento.

A hipótese a ser avaliada é que ficou para o capitalista nacional (dos detentores da riqueza privada aos gestores dos fundos de pensão das estatais) revelar a confiança no futuro do país. Entre as diferentes formas de fuga de capital para o exterior, as oportunidades de financiamento da dívida pública e o nível de investimento de risco no mercado interno é que se faz a definição da taxa real de 
juros, ou seja, do "risco Brasil". O capital estrangeiro, inserido num mercado de informação incompleta, vai utilizar a sinalização do capital doméstico para decidir sobre o nível de risco que vai assumir.

O padrão de governança que prevalece em cada cadeia industrial também desempenha um papel importante para atrair o capital de risco estrangeiro. Mas é a capacidade de domínio tecnológico e de inovação do empresário nacional, junto com a previsibilidade das nossas agências reguladoras, que determinam as estratégias possíveis de governança.

Em uma sociedade desigual, sempre haverá espaço para lideranças clandestinas desenvolverem estratégias bem-sucedidas de mobilização dos grupos menos representados pelo processo político organizado. Isso vai desde "empresários de liminares" garantindo a evasão fiscal às quadrilhas de seqüestradores e aos traficantes que comandam favelas nas maiores áreas metropolitanas, compondo um quadro de elevada insegurança. A garantia de direitos de propriedade e dos contratos é apenas mais um episódio dentro desse quadro.

O sistema de previdência exerce papel muito importante no processo de desenvolvimento pelo seu papel de concentrador de poupança e, simultaneamente, de desconcentrador da renda. O nosso sistema, no entanto, parece cumprir o papel inverso, pela ação de captura de benefícios privilegiados por grupos da burocracia, a partir da Constituição de 1988, por funcionários das empresas estatais e por quadrilhas que desviam recursos de forma crônica.

O crescimento acentuado da carga tributária nos últimos dez anos é fruto de um conflito de jurisdição dentro do acordo federalista brasileiro. Em nossa história republicana, sempre houve oscilação entre períodos com predomínio de características cooperativas e fases com predomínio de elementos competitivos. A Constituição de 1988, em plena fase de redemocratização, exacerbou os elementos de competição por base tributária e de descentralização da prestação dos serviços públicos para Estados e Municípios, por via do aumento das transferências compulsórias. A reação do governo central foi a de elevar os tributos que não eram compartilhados com os outros níveis de governo. É lenta, no entanto, a percepção da opinião pública, e pequena sua influência sobre os legisladores, de que esse jogo de poder foi longe demais.

A urbanização acentuada da população, colocando o domicílio mais próximo do ponto de geração dos serviços sociais, e o envelhecimento da estrutura etária da população ajudam a consolidar uma tendência de desequilíbrio nas contas fiscais, aumentar as despesas mais do que a arrecadação. A reversão desse processo é muito mais provável num ciclo de crescimento mais acelerado, portanto não são esses os gastos que devem ser prioritariamente cortados.

A estratégia de completar uma agenda de reformas pontuais (legislação trabalhista, previdência social, tributária etc.) que estamos trilhando desde o início dos anos 1990 parece ser uma história sem fim. Pode restabelecer as condições para a retomada de um ciclo de investimentos, mas também pode revelar 
que a nação padece de uma articulação dos agentes com poder e vontade de promover a redistribuição de renda e do gasto público que vai gerar a contrapartida de poupança doméstica capaz de sustentar o desenvolvimento.

\section{Referências bibliográficas}

BACHA, E.; BONELLI, R. Uma interpretação das causas da desaceleração econômica do Brasil. Revista de Economia Politica, v.25, n.3, p.163, 2005.

DELFIM NETTO, A. Faltava poupança... Valor Econômico, 13.4.2004.

DIAS CARNEIRO, D. Falta coragem para crescer? O Estado de S. Paulo, 22.8.2003.

GOLDENSTEIN, L. Repensando a dependência. São Paulo: Paz e Terra, 1994.

HIRSCHMAN, A. Exit, Voice and Loyalty: Responses to Decline in Firms, Organizations and States. Cambridge: Harvard University Press, 1970.

HIRSCHMAN, A. The Political Economy of Import-Substituting Industrialization in Latin America. The Quarterly Journal of Economics, v.82, n.1, Feb.1968.

MARTINS, L. Estado capitalista e burocracia no Brasil pós-64. Rio de Janeiro: Paz e Terra, 1985.

NAKANO, Y. Estimular a poupança ou o investimento? Valor Econômico, 6.7.2004.

RESUMO - A PROPOSIÇÃO deste artigo é chamar a atenção para a falta de dinamismo da poupança doméstica já no início da década de 1970, quando o investimento era elevado. A razão desse baixo dinamismo está identificada na literatura que analisou o nosso capitalismo dependente. A forma como se deu a ruptura do modelo nacional-desenvolvimentista também é importante para entender as limitações do momento atual. O efeito esperado das reformas econômicas em curso sobre o crescimento econômico fica comprometido, e não será pela execução complementar da agenda que ele voltará a ocorrer. A dificuldade apontada está na natureza social e política do modelo de desenvolvimento; falta a dinâmica dos agentes econômicos básicos (capitalista nacional, multinacional, burocrata e consumidor) como entidades reais detentoras de poder econômico e de representatividade política, temidas umas pelas outras e, portanto, respeitando a regra do jogo (desenvolvimento). O capitalismo nacional precisa de capacitação tecnológica e de inovação, assim como de um padrão de regulação adequado, para recuperar um papel relevante na governança das cadeias industriais. Esse é o elemento de confiança que, junto com as reformas, poderia recuperar um patamar superior de poupança doméstica.

PALAVRAS-CHAVE: Desenvolvimento, Dependência, Poupança, Crescimento, Nacionalismo, Capitalismo, Burocracia, Consumidor, Reformas, Poder, Representação, Tecnologia, Inovação, Regulação, Confiança. 
ABSTRACT - THE PURPOSE of this paper is to call attention to the lack of Brazilian domestic saving since the seventies, when investment was still going high. In the literature of dependent capitalism we find a source of explanation, as well as in the nature of the rupture in the nationalistic development process during the eighties. As a consequence, economic reforms alone will not bring back the dynamics of growth. What is missing is of a social and political nature, the dynamics between basic capitalist agents (national, multinational, burocrats and consumers) real tenants of economic power and political representation, one fearing the other and by due consequence following the rules of the game (development).

KErwords: Development, Dependency, Savings, Growth, Nationalism, Capitalism, Bureaucracy, Consumer, Reforms, Power, Representation, Technology, Innovation, Regulation, Trust.

Guilherme Leite da Silva Dias é professor da Faculdade de Economia e Administração da USP. @ - guildias@usp.br

Recebido em 24.1.2006 e aceito em 27.1.2006. 